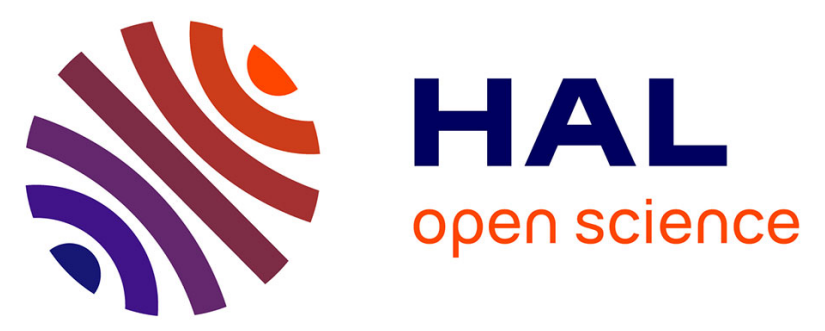

\title{
Past climate changes and strong oceanographic barriers structured low-latitude genetic relics for the golden kelp Laminaria ochroleuca
}

Jorge Assis, Ester Álvares Serrão, Nelson Castilho Coelho, Fernando Tempera, Myriam Valero, Filipe Alberto

\section{To cite this version:}

Jorge Assis, Ester Álvares Serrão, Nelson Castilho Coelho, Fernando Tempera, Myriam Valero, et al.. Past climate changes and strong oceanographic barriers structured low-latitude genetic relics for the golden kelp Laminaria ochroleuca. Journal of Biogeography, 2018, 45 (10), pp.2326-2336. 10.1111/jbi.13425 . hal-01976102

\section{HAL Id: hal-01976102 https://hal.sorbonne-universite.fr/hal-01976102}

Submitted on 9 Jan 2019

HAL is a multi-disciplinary open access archive for the deposit and dissemination of scientific research documents, whether they are published or not. The documents may come from teaching and research institutions in France or abroad, or from public or private research centers.
L'archive ouverte pluridisciplinaire HAL, est destinée au dépôt et à la diffusion de documents scientifiques de niveau recherche, publiés ou non, émanant des établissements d'enseignement et de recherche français ou étrangers, des laboratoires publics ou privés. 
1 Past climate changes and strong oceanographic barriers structured low latitude genetic

2 relics for the golden kelp Laminaria ochroleuca

3 Running title: Climate and ocean currents shaping diversity

4

5 Jorge Assis $^{1 \uparrow *}$, Ester Álvares Serrão ${ }^{1 \dagger *}$, Nelson Castilho Coelho ${ }^{2}$, Fernando Tempera ${ }^{3}$, Myriam

6 Valero ${ }^{4}$, Filipe Alberto ${ }^{5}$

7 *Corresponding authors: jorgemfa@gmail.com, eserrao@ualg.pt

$8{ }^{\dagger}$ Both authors contributed equally to this work.

$9{ }^{1}$ Centre of Marine Sciences, CCMAR-CIMAR, University of Algarve, Campus de Gambelas, 10 8005-139 Faro, Portugal.

$11{ }^{2}$ Department of Computational and Systems Biology, University of Pittsburgh School of

12 Medicine, Pittsburgh, PA 15261, USA

$13{ }^{3}$ MARE - Marine and Environmental Sciences Centre, Centro do IMAR da Universidade dos

14 Açores, Rua Prof. Dr. Frederico Machado, n 4, 9901-862 Horta, Açores, Portugal

$15{ }^{4}$ UMI 3614 Evolutionary Biology and Ecology of Algae, CNRS, Sciences Sorbonne Université,

16 UC, UACH, Station Biologique de Roscoff, 29688 Roscoff Cedex, France

$17{ }^{5}$ Department of Biological Sciences, University of Wisconsin-Milwaukee, 3209 N Maryland

18 Ave, Milwaukee, WI 53211, USA 
21 Aim: Drivers of intraspecific biodiversity include past climate-driven range shifts and

22 contemporary ecological conditions mediating connectivity, but these are rarely integrated in a

23 common comprehensive approach. This is particularly relevant for marine organisms, as ocean

24 currents strongly influence population isolation or connectivity, keeping or diluting the

25 signatures left by past climates. Here we ask whether the coupling between past range shifts and

26 contemporary connectivity explain the extant gene pools of Laminaria ochroleuca, a large brown

27 alga structuring important marine forests from shallow to deep infralittoral grounds.

28 Location: Northeastern Atlantic Ocean

29 Taxon: Laminaria ochroleuca

30 Methods: We estimated population genetic diversity and structure of L. ochroleuca across its

31 entire distribution range using fifteen (15) polymorphic microsatellite markers. This was

32 compared with the outcomes of a paleoclimatic model predicting latitudinal and depth range

33 shifts from the Last Glacial Maximum (LGM) to the present. Genetic differentiation was further

34 compared with potential connectivity inferred with a biophysical model developed with high-

35 resolution data from HYCOM (Hybrid Coordinate Ocean Model).

36 Results: The biogeographic distribution of genetic variability showed overall agreement with the

37 predictions from independently inferred past range shifts. Multiple regions of persistence were

38 identified in deep and upwelling settings at the lowest latitudes of the current species

39 distribution, where higher and unique genetic diversity was retained. The biophysical model

40 revealed that despite the possibility of long-distance migration, contemporary oceanographic

41 barriers strongly restrict connectivity of isolated genetic lineages. 
42 Main conclusions: Integrating different processes at biogeographical scales explained the extant

43 gene pools of marine forests of Laminaria ochroleuca. Low latitude genetic relics harbor a

44 disproportional evolutionary significance, persisting as ancient populations in isolated deep and

45 upwelling climate refugia. Their inferred rates of dispersal may be insufficient to accommodate

46 anticipated climate warming.

47

48 Keywords: climate change; range shifts; connectivity; genetic diversity; marine

49 phylogeography; kelp forests

51 Introduction

52 The climate fluctuations of the Quaternary strongly influenced the dynamics of marine

53 populations (Maggs et al., 2008; Assis et al., 2014, 2016; Neiva et al., 2016). During glacial

54 periods (e.g., Last Glacial Maximum, LGM; 21,000 yr BP), the higher latitudinal range margins

55 of cold- to warm temperate species often retreated, particularly in the northern hemisphere, due

56 to both sea surface temperatures (North Atlantic winter sea temperatures anomalies amount to

$57 \sim 10{ }^{\circ} \mathrm{C}$; Strandberg et al., 2011) and advance of continental ice sheets (Hewitt, 2004). The

58 restriction of populations to small suitable regions beyond ice margins (i.e., refugia) is frequently

59 hypothesized (Provan \& Bennett, 2008; Neiva et al., 2016) but large low latitude expansions

60 were also likely (Kettle et al., 2011; Assis et al., 2017a). In contrast, during warmer interglacial

61 periods (e.g., Holocene; 12,000 yr BP to present time), refugial populations gradually

62 recolonized formerly glaciated regions (Maggs et al., 2008; Provan \& Bennett, 2008; Neiva et 
63 al., 2016), and range contractions might have occurred at lower latitudes (Assis et al., 2014, 64 2016).

65 The demographic history of populations can be reflected in the present distribution of genetic

66 diversity. Under extreme climate conditions, populations might have lost genetic diversity if

67 effective sizes decreased drastically, increasing genetic drift (Provan, 2013), bottlenecks and

68 local extinctions. Even more pervasive reductions of diversity could take place during range

69 expansions owing to founder effects at leading edges (Excoffier et al., 2009; Neiva et al., 2012a;

70 Assis et al., 2016). Conversely, in regions that kept long-term suitable habitats, persistent

71 populations could accumulate ancient genetic diversity (Hewitt, 2004; Maggs et al., 2008;

72 Provan, 2013; Assis et al., 2016; Neiva et al., 2016). The number and isolation of refugia may

73 have also played an important role in shaping the genetic variation of species (Assis et al., 2014).

74 The paradigm of range-shifting effects of past climate events might not be sufficient to explain

75 the present patterns of diversity, as it may be changed by widespread contemporary dispersal

76 (Silva et al., 2014) or local habitat conditions (Assis et al., 2016; Lourenço et al., 2016). For

77 marine organisms, ocean currents influence relative isolation and connectivity of populations

78 (e.g., Coleman, 2013; Pereyra et al. 2013; Buonomo et al., 2016; Lourenço et al., 2017), keeping

79 or diluting the signatures left by past climate changes (Lourenço et al., 2017). Dispersal

80 predictions are increasingly compared with genetic estimates, but not along species ranges (e.g.,

81 Billot et al., 2003; Alberto et al., 2011; Coleman, 2013; Buonomo et al., 2016). Species with

82 restricted dispersal generally hold fine-scale genetic differentiation (e.g., seaweeds: Neiva et al.,

83 2012b; Assis et al., 2013; Robuchon et al., 2014), while those with larger dispersal probabilities

84 (having larval stages) tend to have variable or little phylogeographic structure (e.g., mussels:

85 Lourenço et al., 2017; pelagic fish: Silva et al., 2014, benthic fish: Klein et al., 2016). In benthic 
marine organisms, depth range shifts, the equivalent to terrestrial elevation shifts, may further

87 permit long-term persistence of ancient gene pools. Populations colonizing deeper colder waters

88 may safeguard diversity during warming periods, regardless of their inherent dispersal ability

89 (Graham et al., 2007; Santelices, 2007a; Assis et al., 2016). Likewise, coastal upwelling regions

90 may generate pockets of cryptic refugia preserving regional diversity in the face of climate

91 changes (Lourenço et al., 2016).

92 Disentangling how past climate changes and dispersal ecology structured the distribution of

93 intraspecific diversity is of much biogeographical and evolutionary relevance, although only a

94 few studies combined both processes (e.g., Lourenço et al., 2017). Furthermore, while the role of 95 refugia in poleward expansions is well documented (e.g., Neiva et al., 2016), range shifts at low

96 latitudes are insufficiently understood. Most importantly, describing the processes shaping

97 endemic genetic lineages is timely, as their persistence might be threatened by climate changes

98 (Provan \& Maggs, 2012; Assis et al., 2017a; Wernberg et al., 2018).

99 A good model to explore the aforementioned topic is the golden kelp Laminaria ochroleuca 100 Bachelot de la Pylaie, 1824. These large brown algae structure marine forests providing many 101 ecosystem functions (Araújo et al., 2016). Its niche matches thermal physiological responses (10 102 to $24^{\circ} \mathrm{C}$; Assis et al., 2017b), a crucial feature to track climate-driven range shifts. Long-range 103 dispersal by this species is likely to occur by rafting and not spore dispersal, as kelp spores have 104 short viability ( 1 day; Reed et al., 1992; Pereira et al., 2011), settling within tens of kilometers 105 maximum (Gaylord et al., 2002). Whole individuals of L. ochroleuca cannot float, but multiple 106 reports of Laminaria rafting (Thiel \& Gutow, 2005) indicate that fragments may become buoyant 107 and/or entangled in other rafts (Thiel \& Gutow, 2005; Clarkin et al., 2012). Since reproductive 108 blades may remain viable for long time (Thiel \& Gutow, 2005), dispersal distances may extend 
109 to hundreds of kilometers (e.g., Hernández-Carmona et al., 2006). Additionally, a paleoclimatic

110 niche model for this species estimated low latitude persistent populations, some in deep and

111 upwelling settings (Assis et al., 2017a), likely to retain ancient genetic biodiversity (Assis et al.,

112 2016; Lourenço et al., 2016).

113 In this paper, we ask whether extant rich gene pools of L. ochroleuca can be explained by past

114 climate-driven range shifts, coupled with contemporary dispersal mediated by ocean currents.

115 We matched persistence predictions of a paleoclimatic model (Assis et al., 2017a) against

116 endemic genetic diversity and potential oceanographic connectivity. We hypothesize that (1)

117 climatic refugia display higher and endemic genetic diversity relative to to more recent

118 populations and that (2) effective long-distance dispersal is rare, restricting the homogenization

119 of populations and isolating important biodiversity hotspots.

\section{Methods}

\section{Study area and focal species}

123 The study area comprised the entire distributional range of Laminaria ochroleuca, from

124 Cornwall (50.0N, 5.5W; England) to Sesimbra (38.4N, 9.2W; Portugal), plus isolated regions

125 where it occurs beyond the more continuous range: Alboran Sea, Morocco upwelling spots,

126 seamounts and Azores islands (Araújo et al., 2016; Assis et al., 2017a). Along continental

127 coastlines, the species is vertically distributed from intertidal pools down to ca. $30 \mathrm{~m}$ depth. In

128 the clearer waters of shallow seamounts, islands and the Mediterranean, it can reach 50-80 m

129 depth (e.g., Formigas bank, shallow seamounts off southwestern Iberia, Alboran Sea and Strait of 
130 Messina). This is a perennial species with a heteromorphic life cycle alternating between

131 macroscopic sporophytes and microscopic gametophytes.

\section{Genetic diversity and structure}

134 Approximately 30 individuals were sampled haphazardly per site (dependent on abundance and 135 accessibility) for genetic analyses (24 sites; Fig. 1a), by removing a piece $\left(\sim 1 \mathrm{~cm}^{2}\right)$ from the base 136 of the blade. Genomic DNA was extracted using NucleoSpin96 PlantKit II (Macherey-Nagel,

137 Germany). Microsatellite amplification and scoring was performed for 15 polymorphic loci as in 138 Coelho et al. (2014).

139 Genetic diversity per site and genetic group (see structure analysis below) was estimated as 140 allelic richness, private alleles and gene diversity (expected heterozygosity). Sample sizes were

141 standardized to the smallest in any population (excluding those $\leq 10$ ), using $10^{4}$ randomizations.

142 To test the role of refugia, standardized genetic diversity was determined separately for regions

143 of persistence and post-LGM settlements, identified in Assis et al. (2017a; Fig. 1a). The null

144 expectation for refugia was tested as the proportion of $10^{4}$ randomizations retrieving higher

145 diversity and endemism (i.e., private alleles). $F_{\text {IS }}$ and departures from Hardy-Weinberg

146 equilibrium were tested per site with Fstat (Goudet, 1995) under $10^{4}$ randomizations of alleles

147 among individuals, and individuals within sites.

148 Genetic structure was inferred with Structure (Pritchard et al., 2000) without a priori population 149 assignment and allowing admixture. This analysis was performed for a range of genetic groups,

150 by running the model of correlated allele frequencies with a burn-in time of $2 \times 10^{5}$ repetitions and $15110^{6}$ iterations. The number of groups was inferred with the DeltaK criterion (Evanno et al., 
152 2005). An additional level of genetic structure was inferred by running a second analysis within

153 genetic groups. Two sites showing admixture in the first hierarchal run (see results below) were

154 included in the pool of each genetic group to better disentangle genetic structure.

155 Genetic differentiation was estimated between sites and genetic groups with Jost's D. This was

156 used in detriment of $F_{\mathrm{ST}}$ because it is more appropriate to compare populations with contrasting

157 levels of genetic diversity (Jost, 2008; Whitlock, 2011; Assis et al., 2016), as in our case (see 158 results).

160 Connectivity potential

161 Simulations of potential connectivity used a biophysical model following Buonomo et al. (2016),

162 Klein et al. (2016) and Cunha et al. (2017), with daily data from the Hybrid Coordinate Ocean

163 Model (HYCOM; Chassignet et al., 2007). This high-resolution hindcast accurately reproduces

164 key oceanographic processes like fronts, meandering currents, filaments and eddies (Chassignet

165 et al., 2007; Lett et al., 2008), and its main limitation lies on the inability to simulate processes at

166 scales below its raw resolution ( $7 \mathrm{~km}$ at mid-latitudes; Fossette et al., 2012). While this can

167 constrain seascape genetic studies focusing on nearshore processes, it may be neglected at the

168 scales of our genetic sampling.

169 The simulation comprised the $\sim 5000 \mathrm{~km}$ of the study area, gridded to $0.01^{\circ}$ spatial resolution $(\sim 1$

$170 \mathrm{~km}$ ). Virtual particles were released from each cell, daily from April to September. This period

171 covers the reproductive stages that can potentially fragment and drift, releasing spores after

172 dispersal (Thiel \& Gutow, 2005; Clarkin et al., 2012) even when rafting for long time (Macaya et

173 al., 2005). Particles were allowed to drift until reaching shore, and their position was determined 
174 hourly with bilinear interpolation on the velocity fields of currents (Klein et al., 2016; Cunha et

175 al., 2017). Since real dispersal times of L. ochroleuca are unknown, different simulations were

176 performed with contrasting thresholds of: 1 day, for dispersal by spores, as sporulation lasts 15-

$17718 \mathrm{~h}$ (Pereira et al., 2011) and spores stop swimming after $\sim 24 \mathrm{~h}$ (inferred for Macrocystis

178 pyrifera and Pterygophora californica; Reed et al., 1992); 30 days, considering long-lived rafts,

179 in line with the period estimated for other brown algae (Thiel \& Gutow, 2005; Monteiro et al.,

180 2016); 60 days, for longer-lived rafts.

181 The probability of connectivity was computed by dividing the number of particles released from

182 a given cell $i$ that ended on cell $j$, by the total number of particles released from cell $i$.

183 Oceanographic variability was taken into account by running independent simulations for the 184 most recent 10-year period available in HYCOM (i.e., from 2003 to 2012). A final asymmetrical

185 connectivity matrix was produced by averaging the products of the annual simulations. To

186 consider the hypothesis of year-to-year stepping-stone migration, a network analysis was

187 implemented, in which vertices were the cells and edges the probabilities of transport between

188 them (e.g., Buonomo et al., 2016). Connectivity was estimated as the shortest path between cells,

189 i.e., the one that minimizes the sum of negative log-transformed probabilities across all possible

190 paths (Floyd-Warshall's algorithm).

191 The role of ocean currents was tested with linear regression models fitting genetic differentiation

192 (Jost's D) against probability of stepping-stone connectivity between the sites sampled for

193 genetics. The models considered the dispersal periods of 1,30 and 60 days. A null model of

194 isolation by distance was built by fitting genetic differentiation against alongshore marine

195 distances. The models were compared using adjusted R-square, Pearson's correlation coefficient

196 and Akaike Information Criteria (AIC). 
197 Network community detection was used to identify the major oceanographic regions of the study

198 area, i.e., those with higher within-region connectivity (e.g., Cunha et al., 2017; Lourenço et al.,

199 2017). Excessive connections with unimportant information in the stepping-stone connectivity

200 matrix were removed until a threshold maximizing the goodness of fit index of Modularity

201 (Newman, 2006). The leading eigenvector algorithm (Newman, 2006) used the percolated

202 network to assign a unique membership (oceanographic region) to each vertex. The significance

203 of regions was tested by computing the proportion of $10^{4}$ random assignments of memberships

204 retrieving higher Modularity than observed.

205 Dispersal simulations and network analyses were implemented in R (R Development Core Team,

206 2016) with packages: data.table, dismo, doparallel, gstat, igraph, raster and vegan.

208 Results

209 Genetic diversity and structure

210 A total of 262 alleles were found across 649 genotyped specimens. Southern diversity was

211 generally higher, decreasing northwards. Allelic richness (Table 1) was higher in Tarifa $(\hat{\mathrm{A}}>6)$

212 than in all other sites $(\hat{\mathrm{A}}<5)$. Endemism (i.e., private alleles; Table 1) ranged from very high in

213 southern isolated sites of Formigas and Tarifa to nearly no private diversity in several more

214 northern sites (e.g., Plymouth, Port Blanc, Barrañán). Gene diversity (Table 1), like allelic

215 richness, was highest in Tarifa. Lower diversity and endemism were found in northern sites, and

216 where no standardization was implemented due to low sample size. Significant heterozygote

217 deficit was found in only 1 out of 25 sites (Table 1).

218 When considering the paleoclimatic model for L. ochroleuca, genetic diversity was higher within 
219 refugia (i.e., western Iberia, the Iberian Seamounts, Gibraltar Strait, western Morocco and the

220 Azores; Fig. 1a), accounting for approximately 2-fold higher diversity and 7-fold more private

221 alleles than in regions of post-LGM settlements (i.e., Galicia in northwestern Iberia and western

222 English Channel; Fig. 1a).

223 The first hierarchal level of Structure analysis revealed (1) a north group including all continental

224 sites from Plymouth southwards to Ericeira and the Iberian Seamounts, (2) a south group

225 including Tarifa, Morocco and the Azores (Formigas), and (3) an admixture zone in Sesimbra

226 and Espichel (Fig. 2). The second level divided the north group in (1) Western English Channel,

227 (2) Western Iberia and (3) Iberian Seamounts. The south group was divided into four sub-groups

228 corresponding to each site (Fig. 2). The admixture zone grouped with Western Iberia (refer to S1

229 for DeltaK criterion).

230 Allelic richness per genetic group (second hierarchical level) was higher in Tarifa, followed by

231 El Jadida, Western Iberia and the Iberian Seamounts (Fig. 2d). Much more private diversity was

232 found in Tarifa (21.2), Formigas and El Jadida. Considering both Moroccan sites, the private

233 diversity of Morocco (16.4) is similar to that in Formigas (16.7). The Western English Channel

234 showed the lowest diversity and endemism (Fig. 2d). Pairwise differentiation (Jost's D) between

235 groups was lower between the three northernmost groups, and also between Tarifa and Essaouira

236 (Fig. 2e). Highest differentiation was between Formigas and all groups (Fig. 2).

\section{Connectivity potential}

239 Genetic differentiation was best explained by stepping-stone connectivity considering dispersal 240 up to 30 days (Fig. 3a; p-value: < 0.001; adjusted $\mathrm{R}^{2}$ : 0.643; Pearson's cor: -0.798 ; refer to $\mathrm{S} 3$ for 
241 additional models). The simulations further showed that although dispersal events may occur

242 over dozens to thousands of kilometers, only $5 \%$ go beyond $3.93 \mathrm{~km}$ (Fig. 3c). The identification

243 of oceanographic regions for L. ochroleuca retrieved a significant modularity of 0.827 (p-value:

$244<0.001$; Fig. 3b). This analysis identified fifteen regions, eleven of which within the species’

245 distribution (Fig. 3b).

247 Discussion

248 This study demonstrates that the distribution of population genetic diversity across species

249 ranges can be highly skewed and structured by processes acting at different scales. By combining

250 theoretical modelling with empirical genetic data, we reveal how range shifts of the recent past

251 (ca. 20,000 yr BP) structured regions of long-term persistence at low latitude (warmer) range

252 margins, where higher and unique genetic diversity was retained. Simulating the potential degree

253 of connectivity further allowed estimating well-defined barriers shaped by physical

254 oceanographic transport, which restrict homogenization of extant populations, leaving genetic

255 biodiversity hotspots demographically and genetically isolated.

257 Past climate changes structuring genetic diversity

258 The overall genetic diversity distribution of L. ochroleuca corroborated expectations underlying

259 estimated past range shifts. The paleoclimatic niche model identified multiple refugia presently

260 located at lower latitudes. These locations displayed significantly higher genetic diversity and

261 disproportional endemism, when compared to populations estimated to be much younger. As in 
262 other species (Assis et al., 2016; Neiva et al., 2016), persisting within refugia might have been

263 central to preserve and accumulate genetic diversity. In contrast, founder effects at the leading

264 edge of post-LGM settlements might have produced successive bottlenecks (Excoffier et al.,

265 2009), reducing diversity of higher latitude populations beyond refugia (i.e., Galicia and western

266 English Channel). Such an extremely skewed pattern of genetic diversity contrasts with that of

267 several other brown algae, which currently display higher diversity in the central region of their

268 distributions (Coyer et al., 2003; Hoarau et al., 2007; Assis et al., 2014; Robuchon et al., 2014),

269 despite the uniqueness (i.e., private alleles) of their lower diversity at warmer edges. Lower

270 diversity of endemic genetic lineages at such range margins indicates genetic erosion (if not

271 complete extinction; Nicastro et al., 2013) despite long evolutionary time.

272 Remarkably, although the hotspots of endemic diversity for L. ochroleuca occur at the warmer

273 range margins, all are in upwelling coldspots receiving cold nutrient-rich waters (Gibraltar Strait,

274 Morocco, Azores). Offshore seamounts may further retain ancient diversity during warming

275 periods (Assis et al., 2016), as increased light penetration allows deeper (colder) settlements

276 (Graham et al., 2007; Santelices, 2007a; Assis et al., 2017b). The diversity patterns found in the

277 deep populations of the Azores and the Iberian seamounts support the refugial hypothesis,

278 however, the high differentiation of the Azores indicates that this region was colonized much

279 earlier than the separation of all other populations and has remained isolated since then. In

280 Iberian seamounts, fringe environments with steep bathymetric slope (Santelices, 2007b; Assis et

281 al., 2017a) might hypothetically restrict population sizes and promote a large effect of genetic

282 drift, reducing diversity by purging low frequency alleles over time (Young et al., 1996). The

283 isolation of such regions, hundreds of kilometers offshore, may further prevent gene flow from

284 genetically-distinct populations, a process that can further decrease diversity relative to refugium 
expectations (Hewitt, 2004). Similar population size limitations could have been expected for the

286 small upwelling region of Tarifa and the steep slopes of volcanic islands of the Azores. Yet the

287 high endemic genetic diversity of these two regions indicates that either there have not been

288 major bottlenecks there, or the diversity is still significant but reflects a shifted baseline from an

289 even richer state.

290 Western Iberia was also predicted as persistent climate refugium, as suggested also by the high

291 private diversity (see Sesimbra, Amorosa, Peniche). However, compared to refugia further south,

292 it has lower diversity. This refugium was the northern range margin during colder periods (like

293 the LGM, Fig. 1b) and is presently the southern range margin of the continuous continental

294 distribution. Thus, it might have experienced genetic drift and bottlenecks owing to reduced

295 population sizes while occurring near niche thresholds (Eckert et al., 2008; Oppliger et al.,

296 2014). Even when climate conditions in this region approximated niche optimum, priority

297 colonization effects (Tellier et al., 2011; Neiva et al., 2012b) and/or strong oceanographic

298 barriers (see discussion below) could have limited gene flow from richer populations. Also, one

299 cannot discard the uncertainty of paleoclimatic models (Pearson et al., 2006), which could

300 overrate the refugial potential of some regions. The climate data used for the LGM predictions

301 might underestimate winter cooling of western Iberia (Ramstein et al., 2007), rendering local

302 extinctions if temperatures dropped below the $10^{\circ} \mathrm{C}$ limit (Assis et al., 2017a). However, the

303 genetic data do not support this possibility, given the considerable private diversity of this

304 region, even when each population is considered separately (e.g., Sesimbra, Amorosa and

305 Peniche). 
308 We discovered that L. ochroleuca has two main genetic groups, which coincide with the regions

309 of persistence over the cold and warm climate maxima (Assis et al., 2017a). Within lineages,

310 further structure was revealed, comprising seven groups. Their significant differentiation

311 indicates low gene flow, not counterbalancing genetic drift and/or mutation.

312 The simulations of connectivity suggest the possibility of long distance dispersal, up to 30 days.

313 Despite the expected 1-day kelp spore viability (Reed et al., 1992), Laminaria are recurrently

314 recorded rafting offshore (Thiel \& Gutow, 2005) and L. ochroleuca crossed the English Channel

315 and reached the Azores in the mid-Atlantic. Paradoxically, despite the possibility of such events,

316 L. ochroleuca and other kelp maintain strong genetic structure (Fraser et al., 2010; Johansson et

317 al., 2015; Assis et al., 2016), suggesting that long effective dispersal (i.e., resulting in settlement

318 and recruitment) is possible but very rare, in agreement with our simulations, as rafts unable to

319 accomplish connectivity in the first days are typically lost in the open ocean (also demonstrated

320 for other large brown algae; Buonomo et al. 2017). This further agrees with its low expansion

321 potential along the English Channel (5 km/year; Straub et al., 2016). Moreover, priority

322 colonization in well-established populations (Tellier et al., 2011; Neiva et al., 2012b) may block

323 effective dispersal by later migrants. Our data show that dispersal over long distances is not

324 common in L. ochroleuca, preventing the homogenization of phylogroups, but must have been

325 crucial for colonization of distant habitats across large water masses (e.g., Iberian seamounts and

326 the Azores) and during post-glacial expansions.

327 Connectivity simulations identified 11 oceanographic regions within the species range, that

328 largely match the distribution of genetic groups, particularly in lower latitudes (i.e., Iberian 
329 Seamounts, Alboran, Morocco and Azores). However, colonization pathways can be

330 hypothesized from our genetic data for the more recent populations in the English Channel and

331 Galicia, both appearing derived from the Iberian refugium. The former could have resulted from

332 a (rare) long-distance dispersal from a population similar to that currently present in Viana do

333 Castelo (less differentiated) towards Brittany, followed by Channel crossing. Founder effects

334 during these events would have shaped the distinct genetic group found in this northern range

335 (Neiva et al., 2012b; Assis et al., 2016). Galicia could have been colonized by near shore range

336 expansion, hypothetically starting from a population similar to that observed in Amorosa. There

337 is no evidence of any involvement of the remaining lower latitude populations in northern

338 colonizations. Indeed, expansions by low dispersal species tend to be mediated by few

339 individuals that happen to be located at the leading edge of the expanding front (Hoarau et al.,

340 2007; Excoffier et al., 2009; Neiva et al., 2012a; Assis et al., 2016).

341 The temporal scale of range expansions may surpass the contemporary oceanographic processes

342 simulated in the present study, preventing connectivity with distant regions, across large water

343 masses. In particular, our results of ocean transport could not explain migration to the Azores,

344 even for 2 months of potential dispersal (Refer to S4). However, there are several records of cold

345 temperate algae found drifting in the Azores, even though they do not occur there (e.g.,

346 Ascophyllum nodosum; Neto, 1994), which could originate from both sides of the Atlantic with

347 increased dispersal periods (Putman \& He, 2013). Also, long-distance events might have

348 occurred more frequently in a past with different oceanographic patterns and glacial coastlines,

349 such as when the LGM sea level dropped $-120 \mathrm{~m}$ (e.g., Peltier, 2004), potentially increasing

350 stepping stone connectivity (Fig. 1b) through habitats that are submerged today (Assis et al.,

351 2016). Human-mediated transport cannot explain the establishment of such remote populations 
352 of L. ochroleuca because these are so genetically distinct that their existence is expected to be

353 much more ancient than the colonization of the Azores by humans. In contrast, colonization by

354 Fucus serratus of Atlantic North America is correlated with historical shipping pathways, but

355 population divergence is still very low (Brawley et al., 2009).

356 Oceanographic barriers may maintain contact zones between parapatric populations, with high

357 but not unique local diversity, due to admixture. This may be the case for the admixture region

358 (Arrábida) between the two main lineages of L. ochroleuca, over an oceanographic barrier in

359 front of the Tagus estuary. Contact zones may also increase regional homozygosity if

360 differentiated gene pools have some reproductive isolation (Wahlund effect). While this was not

361 verified in Arrábida, it could hypothetically explain homozygote excess in São Bartolomeu do

362 Mar, where an oceanographic barrier was identified separating northwest from western Iberian

363 shorelines.

364 Concluding, our results show key roles of multiple refugia (from past climate changes) in 365 safeguarding most of the species genetic diversity. Simulating connectivity further showed how

366 such biodiversity hotspots are kept isolated by contemporary ocean currents (oceanographic

367 barriers). While the present range of L. ochroleuca shows that long-distance dispersal is possible,

368 our results suggest that these events are rare.

369 The strong divergence and endemism of low latitude populations, coupled with their strong

370 oceanographic isolation, represent the most remarkable feature of the species phylogeography.

371 These populations, occurring mostly in deep or upwelled pockets within the warmer range

372 margin, have not contributed to post-LGM expansion. These traits are not unique to $L$.

373 ochroleuca (e.g., Neiva et al., 2014; Johansson et al., 2015; Assis et al., 2016) and render a 
374 disproportionate evolutionary significance to marine forest refugia populations. Their

375 hypothetical future loss could dramatically reduce genetic diversity and compromise adaptive

376 potential (Hampe \& Petit, 2005; Provan \& Maggs, 2012; Wernberg et al., 2018), also causing

377 ecosystem changes in overall richness and biomass of associated species (Hoegh-Guldberg \&

378 Bruno, 2010).

379 The general agreement between paleoclimatic models and observed genetic diversity suggests

380 broad niche conservatism, implying low plasticity and adaptive potential on a wide scale. Low

381 latitude refugial regions are in risk of disappearing, even when associated with upwelling

382 (Gibraltar and Morocco for L. ochroleuca; Assis et al., 2017a). This might not be compensated

383 by reported and predicted poleward expansions (Smale et al., 2015; Assis et al., 2017a) because

384 we showed here that low-latitude biodiversity hotspots are not involved in high latitude

385 expansions. In contrast, detrimental climate effects are not expected for the deep refugia of the

386 Iberian seamounts and Azores Islands (Assis et al., 2017a) representing safer sites for ancient

387 diversity than cold upwelling spots. However, currently no empirical evidence distinguishes the 388 different refugial roles provided by both environments.

390 Acknowledgements

391 This study was supported by a Pew Marine Fellowship (USA) and the Foundation for Science

392 and Technology (FCT) of Portugal through postdoctoral fellowship SFRH/BPD/111003/2015

393 and programs CCMAR/Multi/04326/2013, UID/MAR/04292/2013, PTDC/MAR-

394 EST/6053/2014 (GENEKELP), and BIODIVERSA/004/2015 (MARFOR). IMAR-DOP/UAz is

395 R\&D Unit no. 531 also funded by FCT through PEst-OE/EEI/LA0009/2011-2014 (OE, 
COMPETE \& QREN) and by the Azores Fund for Science and Technology (FRCT) through

397 funding schemes RAA and Pró-Convergência. Azores samples were collected during Missão

398 Bancos of IMAR/DOP-UAz led by Pedro Afonso. Further thanks to Jaen Nieto Amat, Norberto

399 Serpa and José Serra, along with the N/I Arquipélago crew.

$400 \quad$ Figures

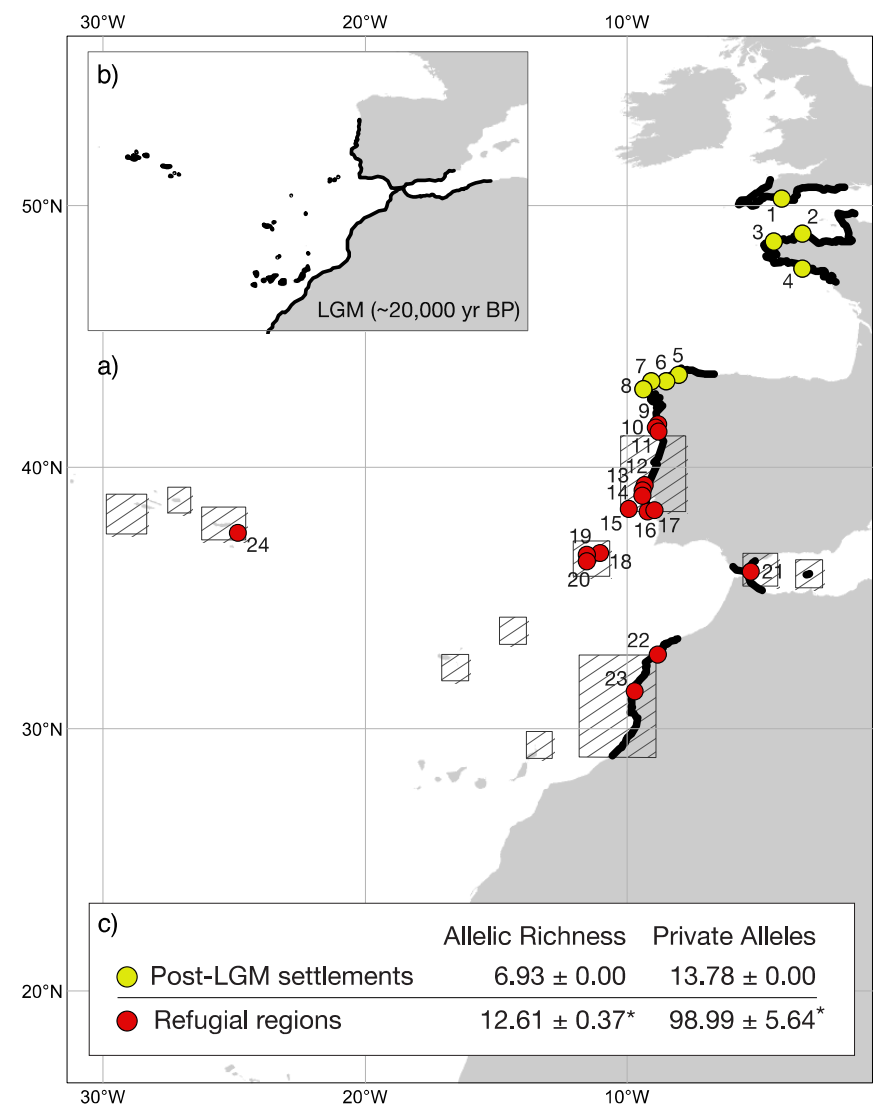

401

402 Figure 1. (panel a) Current distribution of Laminaria ochroleuca (black line; inferred by Assis et 403 al., 2017a; Araújo et al., 2016), sampled sites and refugial regions (striped polygons; Assis et al., 404 2017b). (panel b) Distribution during the Last Glacial Maximum (Assis et al., 2017a). (panel c) 405 Standardized diversity for refugia and post-LGM settlements (* indicates significant values). 
Table 1. Site number (\#) and name, depth (m), sample size (n), standardized allelic richness (Â),

408 private alleles $(\mathrm{PA})$ and expected heterozygosity $(\mathrm{He})(\dagger$ indicates no standardization due to

409 small sample), and $F_{\text {IS }}$ multilocus estimates (* indicates significant deviations from Hardy-

410 Weinberg with Bonferroni correction).

\begin{tabular}{|c|c|c|c|c|c|c|c|}
\hline$\#$ & Site & Depth & $\mathbf{n}$ & $\hat{\mathbf{A}}$ & $\mathbf{P A \hat { A }}$ & He & FIS \\
\hline 1 & Plymouth & 0 & 27 & $2.19 \pm 0.12$ & $0.17 \pm 0.38$ & 0.18 & -0.02 \\
\hline 2 & Port Blanc & 0 & 29 & $2.03 \pm 0.06$ & $0.49 \pm 0.50$ & 0.26 & -0.12 \\
\hline 3 & Brignogan-Plages & 0 & 4 & $2.13 \dagger$ & $1.01 \pm 0.17$ & 0.29 & 0.25 \\
\hline 4 & Lorient & 0 & 15 & $2.33 \pm 0.00$ & $1.97 \pm 0.85$ & 0.27 & 0.07 \\
\hline 5 & A Coruña & 0 & 25 & $3.33 \pm 0.20$ & $1.80 \pm 0.97$ & 0.35 & 0.02 \\
\hline 6 & Barrañán & 0 & 4 & $2.07 \dagger$ & $0.27 \pm 0.45$ & 0.34 & -0.09 \\
\hline 7 & Laxe & 0 & 11 & $2.95 \pm 0.00$ & $1.87 \pm 0.85$ & 0.38 & 0.03 \\
\hline 8 & Camariñas & 0 & 30 & $3.91 \pm 0.13$ & $2.83 \pm 1.11$ & 0.31 & 0.02 \\
\hline 9 & Viana do Castelo & 0 & 38 & $3.33 \pm 0.16$ & $1.49 \pm 0.99$ & 0.33 & 0.06 \\
\hline 10 & Amorosa & 0 & 51 & $4.58 \pm 0.21$ & $3.18 \pm 1.54$ & 0.42 & 0.01 \\
\hline 11 & S. Bartolomeu do Mar & 0 & 39 & $2.10 \pm 0.10$ & $0.94 \pm 0.64$ & 0.28 & $0.31 *$ \\
\hline 12 & Peniche & 0 & 22 & $4.52 \pm 0.18$ & $3.07 \pm 1.15$ & 0.50 & 0.03 \\
\hline 13 & Ribeira de Ilhas & 0 & 3 & $1.93 \dagger$ & $1.00 \pm 0.00$ & 0.49 & 0.34 \\
\hline 14 & Ericeira & 10 & 6 & $2.00 \dagger$ & 0 & 0.24 & 0.37 \\
\hline 15 & Camões seamount & 40 & 7 & $3.00 \dagger$ & $2.11 \pm 0.62$ & 0.42 & 0.04 \\
\hline 16 & Espichel & 10 & 11 & $2.16 \pm 0.00$ & $1.44 \pm 0.58$ & 0.32 & 0.03 \\
\hline 17 & Sesimbra & 10 & 27 & $4.49 \pm 0.22$ & $4.60 \pm 1.52$ & 0.41 & 0.12 \\
\hline 18 & Ormonde seamount & 50 & 46 & $3.30 \pm 0.22$ & $0.73 \pm 0.64$ & 0.35 & 0.04 \\
\hline 19 & Gorringe seamount & 50 & 48 & $3.28 \pm 0.20$ & $2.96 \pm 1.83$ & 0.34 & 0.11 \\
\hline 20 & Gettysburg seamount & 50 & 68 & $3.60 \pm 0.28$ & $2.15 \pm 1.24$ & 0.34 & 0.02 \\
\hline 21 & Tarifa (Gibraltar Strait) & 20 & 52 & $6.38 \pm 0.33$ & $10.19 \pm 2.14$ & 0.53 & -0.01 \\
\hline 22 & El Jadida & 0 & 31 & $4.71 \pm 0.21$ & $8.75 \pm 1.96$ & 0.48 & 0.09 \\
\hline 23 & Essaouira & 0 & 32 & $3.38 \pm 0.13$ & $5.71 \pm 1.72$ & 0.32 & 0.08 \\
\hline 24 & Formigas (Azores) & 50 & 23 & $3.63 \pm 0.18$ & $11.14 \pm 1.87$ & 0.35 & 0.01 \\
\hline
\end{tabular}

411

412 

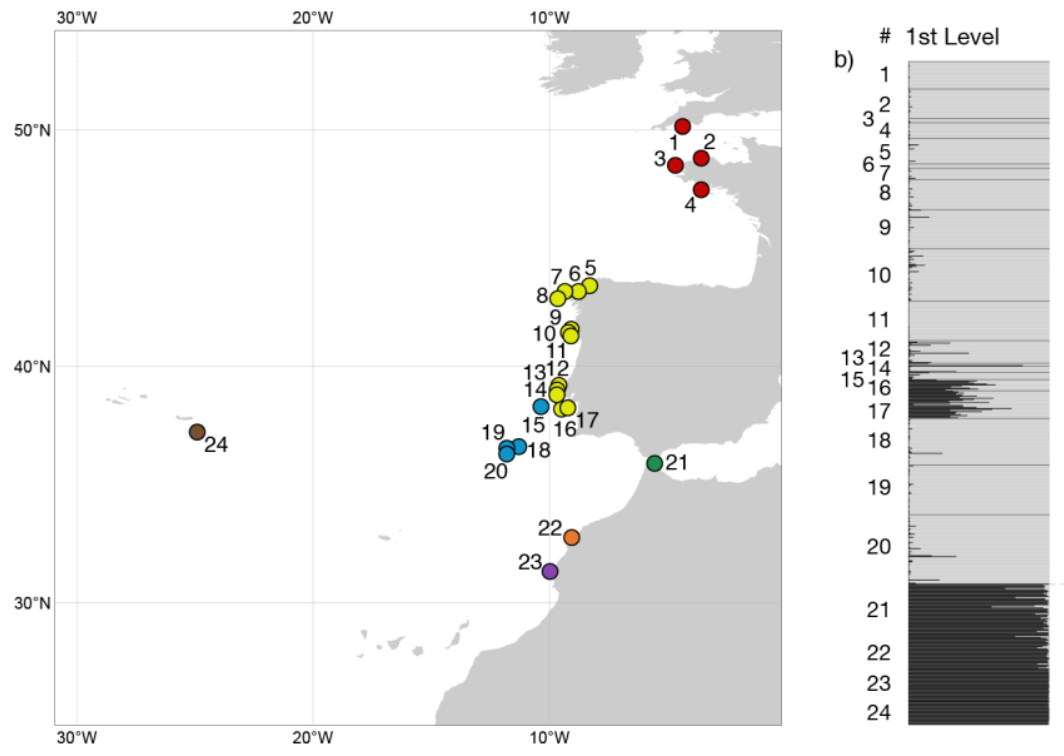

d)

G1 : Western English Channel
Allelic Richness

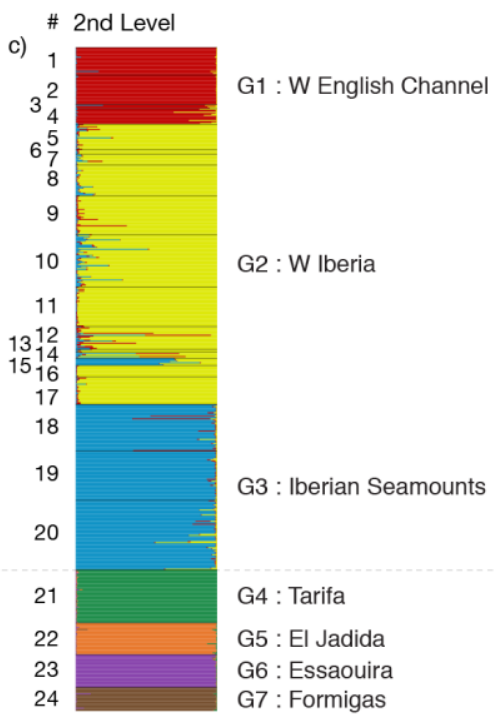

Jost's D

e) G1 G2 G3 G4 G5 G6 G7

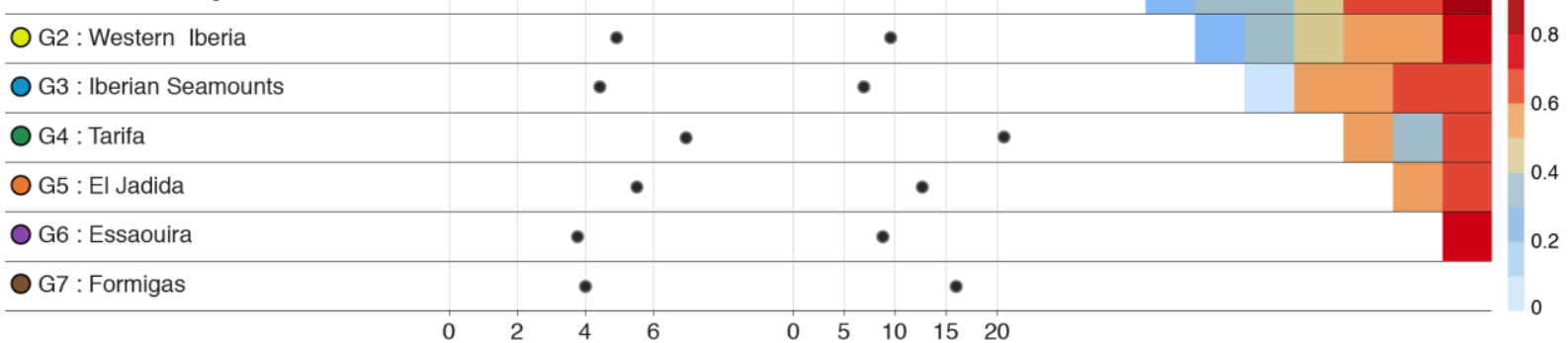

415 Figure 2. (panel a) Sampled sites with colors depicting genetic subdivision inferred with

416 Structure. (panel b) First and (panel c) second hierarchical level of genetic subdivision with

417 Structure. (panel d) Standardized genetic diversity and endemism per genetic group (note:

418 Morocco upwelling region, i.e., G5 and G6 together, have endemic diversity similar to the

419 Azores; see results). (panel e) Population pairwise differentiation (Jost's D, average) between

420 genetic groups. 

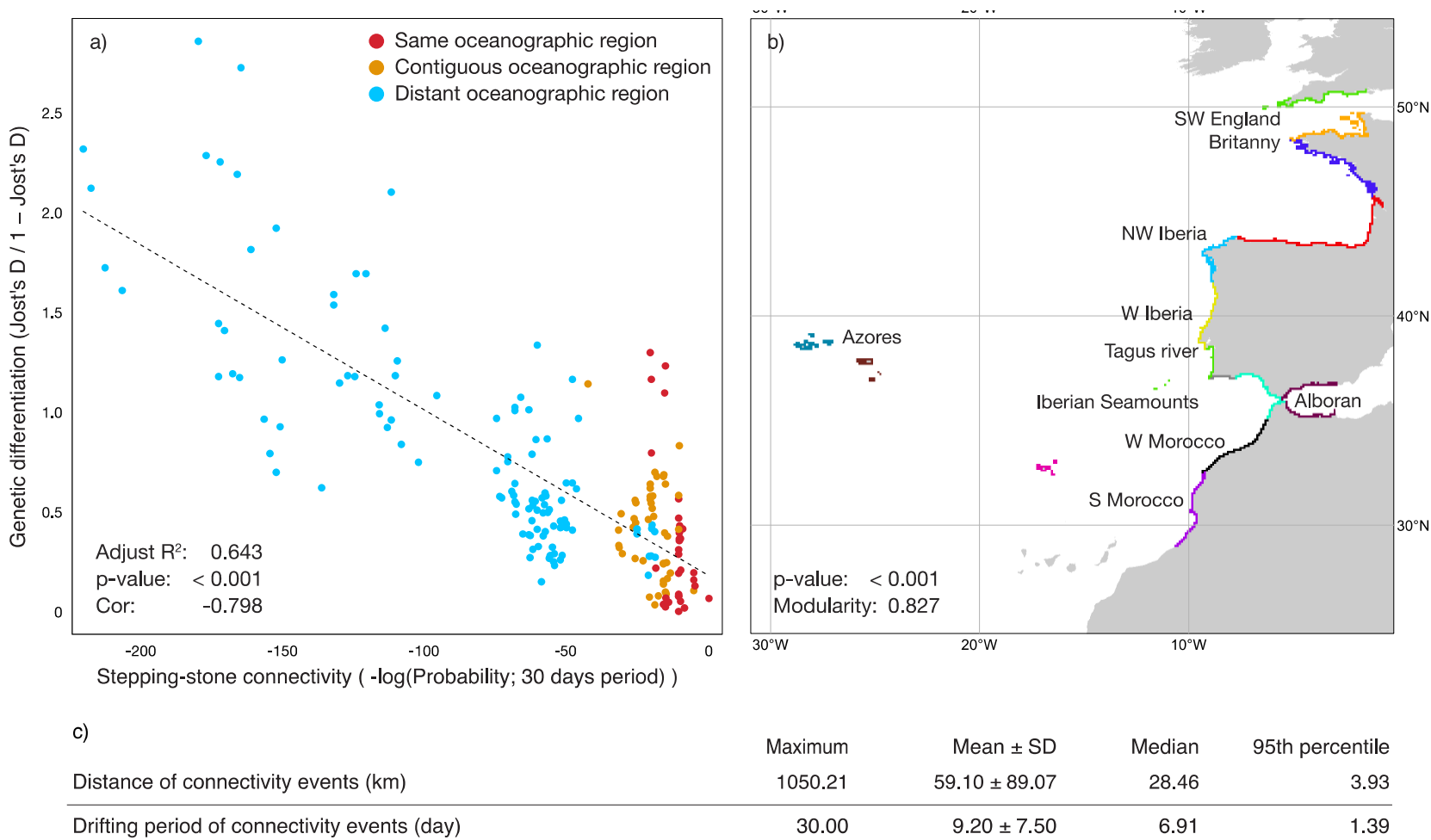

422

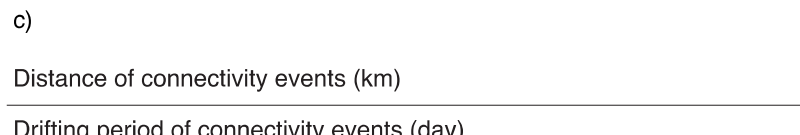

$\begin{array}{llll}30.00 & 9.20 \pm 7.50 & 6.91 & 1.39\end{array}$

423 Figure 3. (panel a) Linear regression of genetic differentiation against probability of connectivity

424 (30 days dispersal period). Colors depicting pairs located in the same oceanographic region (red),

425 in contiguous regions (orange) and non-contiguous regions (blue). (panel b) Oceanographic

426 regions inferred with pairwise connectivity probabilities (depicted as different colors). Names

427 provided for oceanographic regions and barriers of interest. (panel c) Maximum, average,

428 median and 95th percentile distance $(\mathrm{km})$ and drifting period (day) of connectivity events (30

429 days dispersal period).

433 Alberto, F., Raimondi, P.T., Reed, D.C., Watson, J.R., Siegel, D.A., Mitarai, S., Coelho, N., \& 
Serrão, E.A. (2011) Isolation by oceanographic distance explains genetic structure for Macrocystis pyrifera in the Santa Barbara Channel. Molecular Ecology, 20, 2543-2554.

436

437

438

439

440

441

442

443

444

445

446

447

448

449

450

451

452

453

454

Araújo, R.M., Assis, J., Aguillar, R., et al. (2016) Status, trends and drivers of kelp forests in Europe: an expert assessment. Biodiversity and Conservation, 25, 1319-1348.

Assis, J., Araújo, M.B., \& Serrão, E.A. (2017a) Projected climate changes threaten ancient refugia of kelp forests in the North Atlantic. Global Change Biology, 24, 1365-2486.

Assis, J., Coelho, N.C., Alberto, F., Valero, M., Raimondi, P., Reed, D., \& Serrão, E.A. (2013) High and Distinct Range-Edge Genetic Diversity despite Local Bottlenecks. Plos One, 8, e68646.

Assis, J., Coelho, N.C., Lamy, T., Valero, M., Alberto, F., \& Serrão, E.A. (2016) Deep reefs are climatic refugia for genetic diversity of marine forests. Journal of Biogeography, 43, 833844.

Assis, J., Serrão, E.A., Claro, B., Perrin, C., \& Pearson, G.A. (2014) Climate-driven range shifts explain the distribution of extant gene pools and predict future loss of unique lineages in a marine brown alga. Molecular Ecology, 23, 2797-2810.

Assis, J., Tyberghein, L., Bosh, S., Verbruggen, H., Serrão, E.A., \& De Clerck, O. (2017b) BioORACLE v2.0: Extending marine data layers for bioclimatic modelling. Global Ecology and Biogeography, 27, 277-284.

Billot, C., Engel, C.R., Rousvoal, S., Kloareg, B., \& Valero, M. (2003) Current patterns, habitat discontinuities and population genetic structure: The case of the kelp Laminaria digitata in the English channel. Marine Ecology Progress Series, 253, 111-121. 
455 Brawley, S.H., Coyer, J.A., Blakeslee, A.M.H., Hoarau, G., Johnson, L.E., Byers, J.E., Stam, 456 W.T., \& Olsen, J.L. (2009) Historical invasions of the intertidal zone of Atlantic North 457 America associated with distinctive patterns of trade and emigration. Proceedings of the $458 \quad$ National Academy of Sciences of the United States of America, 106, 8239-8244.

459 Buonomo, R., Assis, J., Fernandes, F., Engelen, A.H., Airoldi, L., \& Serrão, E.A. (2016) Habitat $460 \quad$ continuity and stepping-stone oceanographic distances explain population genetic 461 connectivity of the brown alga Cystoseira amentacea. Molecular ecology, 26, 766-870.

462 Chassignet, E.P., Hurlburt, H.E., Smedstad, O.M., Halliwell, G.R., Hogan, P.J., Wallcraft, A.J., 463 Baraille, R., \& Bleck, R. (2007) The HYCOM (HYbrid Coordinate Ocean Model) data

Clarkin, E., Maggs, C.A., Allcock, A.L., \& Johnson, M.P. (2012) Environment, not assimilative system. Journal of Marine Systems, 65, 60-83. characteristics of individual algal rafts, affects composition of rafting invertebrate assemblages in Irish coastal waters. Marine Ecology Progress Series, 470, 31-40.

Coelho, N.C., Serrão, E.A., \& Alberto, F. (2014) Characterization of fifteen microsatellite markers for the kelp Laminaria ochroleuca and cross species amplification within the genus.

471 Coleman, M.A. (2013) Connectivity of the Habitat-Forming Kelp, Ecklonia radiata within and $472 \quad$ among Estuaries and Open Coast. Plos One, 8, e64667.

473 Coyer, J.A., Peters, A.F., Stam, W.T., \& Olsen, J.L. (2003) Post-ice age recolonization and 474 differentiation of Fucus serratus L. (Phaeophyceae; Fucaceae) populations in Northern $475 \quad$ Europe. Molecular Ecology, 12, 1817-1829. 
476 Cunha, R.L., Assis, J., Madeira, C., Seabra, R., Lima, F.P., Lopes, E.P., Williams, S.T., \&

477 Castilho, R. (2017) Drivers of Cape Verde archipelagic endemism in keyhole limpets.

$478 \quad$ Scientific Reports, 41817.

479 Eckert, C.G., Samis, K.E., \& Lougheed, S.C. (2008) Genetic variation across species’

480 geographical ranges: The central-marginal hypothesis and beyond. Molecular Ecology, 17,

$481 \quad 1170-1188$.

482 Evanno, G., Regnaut, S., \& Goudet, J. (2005) Detecting the number of clusters of individuals 483 using the software STRUCTURE: A simulation study. Molecular Ecology, 14, 2611-2620.

484 Excoffier, L., Foll, M., \& Petit, R.J. (2009) Genetic Consequences of Range Expansions. Annual 485 Review of Ecology, Evolution, and Systematics, 40, 481-501.

486 Fossette, S., Putman, N.F., Lohmann, K.J., Marsh, R., \& Hays, G.C. (2012) A biologist’s guide 487 to assessing ocean currents: A review. Marine Ecology Progress Series, 457, 285-301.

488 Fraser, C.I., Thiel, M., Spencer, H.G., \& Waters, J.M. (2010) Contemporary habitat discontinuity 489 and historic glacial ice drive genetic divergence in Chilean kelp. BMC evolutionary biology,

491 Gaylord, B., Reed, D.C., Raimondi, P.T., Washburn, L., \& McLean, S.R. (2002) A physically 492 based model of macroalgal spore dispersal in the wave and current-dominated nearshore. $493 \quad$ Ecology, 83, 1239-1251.

494 Goudet, J. (1995) FSTAT, a program to estimate and test gene diversities and fixation indices. 495 Department of Ecology \& Evolution, Biology Building, UNIL, CH-1015 LAUSANNE, 496 Switzerland. Journal of Heredity, 86, 485-486. 
497 Graham, M.H., Kinlan, B.P., Druehl, L.D., Garske, L.E., \& Banks, S. (2007) Deep-water kelp 498 refugia as potential hotspots of tropical marine diversity and productivity. Proceedings of 499 the National Academy of Sciences of the United States of America, 104, 16576-16580.

500 Hampe, A. \& Petit, R.J. (2005) Conserving biodiversity under climate change: The rear edge $501 \quad$ matters. Ecology Letters, 8, 461-467.

502 Hernández-Carmona, G., Hughes, B., \& Graham, M.H. (2006) Reproductive longevity of 503 drifting kelp Macrocystis pyrifera (Phaeophyceae) in Monterey Bay, USA. Journal of $504 \quad$ Phycology, 42, 1199-1207.

505 Hewitt, G.M. (2004) Genetic consequences of climatic oscillations in the Quaternary. 506 Philosophical transactions of the Royal Society of London. Series B, Biological sciences, $507 \quad 359,183-195$.

508 Hoarau, G., Coyer, J.A., Veldsink, J.H., Stam, W.T., \& Olsen, J.L. (2007) Glacial refugia and 509 recolonization pathways in the brown seaweed Fucus serratus. Molecular Ecology, 16, $510 \quad 3606-3616$.

511 Hoegh-Guldberg, O. \& Bruno, J.F. (2010) The impact of climate change on the world's marine 512 ecosystems. Science, 328, 1523-1528.

513 Johansson, M.L., Alberto, F., Reed, D.C., Raimondi, P.T., Coelho, N.C., Young, M.A., Drake, 514 P.T., Christopher, A., Cavanaugh, K., Assis, J., Ladah, L.B., \& Bell, T.O.M.W. (2015) 515 Seascape drivers of Macrocystis pyrifera population genetic structure in the northeast $516 \quad$ Pacific. Molecular Ecology, 24, 4866-4885.

517 Jost, L.O.U. (2008) GST and its relatives do not measure differentiation. Molecular Ecology, 17, 
Kettle, A.J., Morales-Muñiz, A., Roselló-Izquierdo, E., Heinrich, D., \& Vøllestad, L.A. (2011) Refugia of marine fish in the northeast Atlantic during the last glacial maximum: Concordant assessment from archaeozoology and palaeotemperature reconstructions.

523 Klein, M., Teixeira, S., Assis, J., Serrão, E.A., Gonçalves, E.J., \& Borges, R. (2016) High 524 Interannual Variability in Connectivity and Genetic Pool of a Temperate Clingfish Matches $525 \quad$ Oceanographic Transport Predictions. Plos One, 11, e0165881.

526 Lett, C., Verley, P., Mullon, C., Parada, C., Brochier, T., Penven, P., \& Blanke, B. (2008) A 527 Lagrangian tool for modelling ichthyoplankton dynamics. Environmental Modelling and $528 \quad$ Software, 23, 1210-1214.

529 Lourenço, C.R., Nicastro, K.R., McQuaid, C.D., Chefaoui, R.M., Assis, J., Taleb, M.Z., \& Zardi, 530 G.I. (2017) Evidence for rangewide panmixia despite multiple barriers to dispersal in a 531 marine mussel. Scientific Reports, 1-16.

532 Lourenço, C.R., Zardi, G.I., McQuaid, C.D., Serrão, E.A., Pearson, G.A., Jacinto, R., \& 533 Nicastro, K.R. (2016) Upwelling areas as climate change refugia for the distribution and 534 genetic diversity of a marine macroalga. Journal of Biogeography, 43, 1595-1607.

535 Macaya, E.C., Boltaña, S., Hinojosa, I.A., Macchiavello, J.E., Valdivia, N.A., Vásquez, N.R., 536 Buschmann, A.H., Vásquez, J.A., Vega, J.M.A., \& Thiel, M. (2005) Presence of 537 sporophylls in floating kelp rafts of Macrocystis spp. (Phaeophyceae) along the Chilean 538 Pacific Coast. Journal of Phycology, 41, 913-922. 
Maggs, C.A., Castilho, R., Foltz, D., Henzler, C., Jolly, M.T., Kelly, J., Olsen, J., Perez, K.E.,

540 Stam, W., Väinölä, R., Viard, F., \& Wares, J. (2008) Evaluating signatures of glacial

541 refugia for north atlantic benthic marine taxa. Ecology, 89, S108-S122.

542 Monteiro, C.A., Paulino, C., Jacinto, R., Serrão, E.A., \& Pearson, G.A. (2016) Temporal

543 windows of reproductive opportunity rein- force species barriers in a marine broadcast

$544 \quad$ spawning assemblage. Scientific Reports, 29198.

545 Neiva, J., Assis, J., Fernandes, F., Pearson, G.A., \& Serrão, E.A. (2014) Species distribution

546 models and mitochondrial DNA phylogeography suggest an extensive biogeographical shift

547 in the high-intertidal seaweed Pelvetia canaliculata. Journal of Biogeography, 41, 1137-

$548 \quad 1148$.

549 Neiva, J., Pearson, G.A., Valero, M., \& Serrão, E.A. (2012a) Drifting fronds and drifting alleles:

550 Range dynamics, local dispersal and habitat isolation shape the population structure of the 551 estuarine seaweed Fucus ceranoides. Journal of Biogeography, 39, 1167-1178.

552 Neiva, J., Pearson, G.A., Valero, M., \& Serrão, E.A. (2012b) Fine-scale genetic breaks driven by 553 historical range dynamics and ongoing density-barrier effects in the estuarine seaweed $554 \quad$ Fucus ceranoides L. BMC Evolutionary Biology, 12, 78.

555 Neiva, J., Serrão, E., Assis, J., Pearson, G., Coyer, J., Olsen, J., Hoarau, G., \& Valero, M. (2016)

556 Climate Oscillations, Range Shifts and Phylogeographic Patterns of North Atlantic

557 Fucaceae. Seaweed Phylogeography (ed. by Z.-M. Hu and C. Fraser), pp. 279-308.

$558 \quad$ Springer Netherlands,

559 Neto, A. (1994) Checklist of the benthic marine macro algae of the Azores. Arquipélago Life and 
561 Newman, M.E.J. (2006) Modularity and community structure in networks. Proceedings of the $562 \quad$ National Academy of Sciences, 103, 8577-8582.

563 Nicastro, K.R., Zardi, G.I., Teixeira, S., Neiva, J., Serrao, E.A., Pearson, G.A., Serrão, E.A., \& 564 Pearson, G.A. (2013) Shift happens: trailing edge contraction associated with recent 565 warming trends threatens a distinct genetic lineage in the marine macroalga Fucus 566 vesiculosus. BMC biology, 11, 6.

567 Oppliger, L.V., Von Dassow, P., Bouchemousse, S., Robuchon, M., Valero, M., Correa, J.A., 568 Mauger, S., \& Destombe, C. (2014) Alteration of sexual reproduction and genetic diversity 569 in the kelp species Laminaria digitata at the southern limit of its range. Plos One, 9 , $570 \quad$ e102518.

571 Pearson, R.G., Thuiller, W., Araújo, M.B., Martinez-Meyer, E., Brotons, L., McClean, C., Miles,

572 L., Segurado, P., Dawson, T.P., \& Lees, D.C. (2006) Model-based uncertainty in species 573 range prediction. Journal of Biogeography, 33, 1704-1711.

574 Peltier, W.R. (2004) Global glacial isostasy and the surface of the ice-age earth: the ice-5g (vm2) 575 model and grace. Annual Review of Earth and Planetary Sciences, 32, 111-149.

576 Pereira, T.R., Engelen, A.H., Pearson, G., Serrão, E., Destombe, C., \& Valero, M. (2011)

577 Temperature effects on gametophyte development of L. Ochroleuca and S. polyschides, 578 kelps with contrasting life histories. Cahiers de Biologie Marine, 52, 395-403.

579 Pritchard, J.K., Stephens, M., \& Donnelly, P. (2000) Inference of population structure using 580 multilocus genotype data. Genetics, 155, 945-959. 
581 Provan, J. (2013) The effects of past, present and future climate change on range-wide genetic 582 diversity in northern North Atlantic marine species. Frontiers of Biogeography, 5, 60-66.

583 Provan, J. \& Bennett, K.D. (2008) Phylogeographic insights into cryptic glacial refugia. Trends $584 \quad$ in Ecology and Evolution, 23, 564-571.

585 Provan, J. \& Maggs, C.A. (2012) Unique genetic variation at a species' rear edge is under threat 586 from global climate change. Proceedings of the Royal Society B: Biological Sciences, 279, $587 \quad 39-47$.

588 Putman, N.F. \& He, R. (2013) Tracking the long-distance dispersal of marine organisms: 589 sensitivity to ocean model resolution. Journal of The Royal Society Interface, 10, $590 \quad 20120979-20120979$.

591 R Development Core Team (2016) R: A Language and Environment for Statistical Computing. R 592 Foundation for Statistical Computing, Vienna, Austria.

593 Ramstein, G., Kageyama, M., Guiot, J., Wu, H., Hély, C., Krinner, G., \& Brewer, S. (2007) How 594 cold was Europe at the Last Glacial Maximum? A synthesis of the progress achieved since 595 the first PMIP model-data comparison. Climate of the Past Discussions, 3, 197-220.

596 Reed, D.C., Amsler, C.D., \& Ebeling, A.W. (1992) Dispersal in kelps: factors affecting spore $597 \quad$ swimming and competency. Ecology, 73, 1577-1585.

598 Robuchon, M., Le Gall, L., Mauger, S., \& Valero, M. (2014) Contrasting genetic diversity 599 patterns in two sister kelp species co-distributed along the coast of Brittany, France. $600 \quad$ Molecular Ecology, 23, 2669-2685.

601 Santelices, B. (2007a) The discovery of kelp forests in deep-water habitats of tropical regions. 

$19163-19164$.

604 Santelices, B. (2007b) The discovery of kelp forests in deep water habitats of tropical regions. $605 \quad$ Proc Nat Acad Sci, 104, .

606 Silva, G., Horne, J.B., \& Castilho, R. (2014) Anchovies go north and west without losing 607 diversity: Post-glacial range expansions in a small pelagic fish. Journal of Biogeography, 41, 1171-1182.

Smale, D.A., Wernberg, T., Yunnie, A.L.E., \& Vance, T. (2015) The rise of Laminaria ochroleuca in the Western English Channel (UK) and comparisons with its competitor and assemblage dominant Laminaria hyperborea. Marine Ecology, 36, 1033-1044.

612 Strandberg, G., Brandefelt, J., Kjellström, E., \& Smith, B. (2011) High-resolution regional 613 simulation of last glacial maximum climate in Europe. Tellus, Series A: Dynamic $614 \quad$ Meteorology and Oceanography, 63, 107-125.

615 Straub, S.C., Thomsen Mads, S., \& Wernberg, T. (2016) The Dynamic Biogeography of the 616 Anthropocene: The Speed of Recent Range Shifts in Seaweeds. Seaweed Phylogeography 617 (ed. by Z.-M. Hu and C. Fraser), pp. 63-93. Springer Netherlands,

618 Tellier, F., Tapia, J., Faugeron, S., Destombe, C., \& Valero, M. (2011) The lessonia nigrescens 619 species complex (laminariales, phaeophyceae) shows strict parapatry and complete 620 reproductive isolation in a secondary contact zone. Journal of Phycology, 47, 894-903.

621 Thiel, M. \& Gutow, L. (2005) The ecology of rafting in the marine environment. I. The floating 622 substrata. Oceanography and Marine Biology: an Annual Review, 181-264. 
623 Wernberg, T., Coleman, M.A., Bennett, S., Thomsen, M.S., Tuya, F., \& Kelaher, B.P. (2018)

624 Genetic diversity and kelp forest vulnerability to climatic stress. Scientific Reports, 8, 1-8.

625 Whitlock, M.C. (2011) GST and D do not replace FST. Molecular Ecology, 20, 1083-1091.

626 Young, A., Boyle, T., \& Brown, T. (1996) The population genetic consequences of habitat

627 fragmentation for plants. Trends in Ecology \& Evolution, 11, 413-418.

628

629 Data accessibility

630 Microsatellite data are permanently available at https://doi.org/10.6084/m9.figshare.6275387.v2.

632 Biosketch

633 Jorge Assis is a post-doctoral researcher at CCMAR. His research is mainly focused on the

634 evolutionary consequences arising from climate changes and the drivers mediating gene flow in 635 marine populations.

636

637 Supplementary information

638 S1. Estimation of the number of genetic groups for the first and second hierarchical levels of 639 Structure analyses.

640 S2. Analysis of Molecular Variance and pairwise differentiation levels between sites.

641 S3. Supplementary results for the simulations of potential dispersal. 
642 S4. Stepping stone connectivity matrix (simulation with 60 days dispersal period). 